\title{
Os Direitos Humanos da ONU e o Governo Brasileiro: Uma Análise da Incorporação dos Preceitos da ONU nas Ações Governamentais
}

\author{
Thais Aparecida Dibbern \\ Doutoranda em Política Científica e Tecnológica pela Universidade Estadual de Campinas (Unicamp). Pesquisadora do Laboratório de \\ Estudos do Setor Público da Faculdade de Ciências Aplicadas (FCA) da Unicamp. http://lattes.cnpq.br/9471619073576625. \\ https://orcid.org/0000-0003-4826-4614. dibbern.thais@gmail.com \\ Milena Pavan Serafim \\ Doutora em Política Científica e Tecnológica pela Universidade Estadual de Campinas (Unicamp). Professora doutora da Faculdade de \\ Ciências Aplicadas (FCA) da Unicamp. http://lattes.cnpq.br/0394606527784711. http://orcid.org/0000-0002-7541-4182. \\ milenaps@unicamp.br
}

O debate acerca dos direitos humanos ganhou força preeminente após o reconhecimento das atrocidades e violações cometidas durante a Segunda Guerra Mundial. Ainda que, entretanto, estes sejam positivados em tratados internacionais e outras fontes do direito internacional, bem como estando presentes explicita ou implicitamente nas Constituições, os direitos humanos não ganharam existência real para grande número de pessoas. Com efeito, a ONU surge com recomendações oriundas de diversas agências especializadas e órgãos principais, com mecanismo de Revisão Periódica Universal (RPU) e demais fontes, a fim de contribuir com a situação da proteção e garantia de tais direitos. Em vista disso, este estudo analisa de que forma os instrumentos de planejamento - os Planos Plurianuais - do governo federal incorporam as recomendações oriundas do mecanismo de Revisão Periódica Universal da Organização das Nações Unidas (RPU/ONU) sobre direitos humanos fundamentais. Metodologicamente, a presente pesquisa foi realizada com base em revisões bibliográficas e análise de dados secundários. Como resultados, observa-se que o Estado brasileiro, ao participar de dois ciclos deste mecanismo, aceitou quase todas as recomendações, todavia nem todas foram incorporadas diretamente em seus instrumentos de planejamento e gestão estratégica, isto é, não combatendo propriamente os problemas e desafios elencados nas recomendações recebidas. Palavras-chave: Direitos humanos fundamentais. ONU. Revisão periódica. Ações governamentais. Brasil.

THE HUMAN RIGHTS OF THE UN AND THE BRAZILIAN GOVERNMENT: AN ANALYSIS OF THE INCORPORATION OF RECOMMENDATIONS IN GOVERNMENT ACTIONS

The debate over human rights gained pre-eminence after recognition of the atrocities and violations committed during World War II. However, even if these are positive in international treaties and other sources of international law, as well as being explicitly or implicitly present in the Constitutions, human rights have not gained real existence for large numbers of people. Indeed, the UN comes up with recommendations from a number of specialized agencies, major agencies, the Universal Periodic Review (UPR) mechanism, and other sources, in order to contribute to the protection and guarantee status of such rights. In view of this, this study analyzes how the planning instruments - PPAs - of the Federal Government incorporate the recommendations of the United Nations Universal Periodic Review mechanism on fundamental human rights. Methodologically, the present research was carried out based on bibliographic reviews and analysis of secondary data. As a result, it can be observed that the Brazilian State, when participating in two cycles of this mechanism, accepted almost all the recommendations, however, not all were incorporated directly into its strategic planning and management instruments, that is, not properly combating the problems and Challenges highlighted in the recommendations received.

Keywords: Fundamental human rights. UN. Periodic review. Government actions. Brazil.

SUMÁRIO

1 Introdução. 2 Os Direitos Humanos Fundamentais: Funções e Características. 3 A Organização das Nações Unidas e o Mecanismo de Revisão Periódica Universal. 4 Análise da Incorporação das Recomendações da ONU nas Ações Governamentais. 5 Considerações Finais. 6 Referências. 


\section{INTRODUÇÃO}

O debate acerca dos direitos humanos ganhou força preeminente a partir do reconhecimento das violações cometidas durante a Segunda Guerra Mundial. A partir deste cenário, o qual ocasionou milhares de mortes e a devastação de dezenas de países, foi possível a criação de uma organização supranacional com o objetivo declarado de manter o diálogo entre seus membros, garantir a segurança internacional, bem como o desenvolvimento mundial. Tal organização, fundada oficialmente em 24 de outubro de 1945, composta por países que se reuniram voluntariamente, é conduzida por princípios e valores acordados que possibilitaram grandes conquistas relacionadas a maiores responsabilidades, por parte de seus Estados-membros, na proteção e promoção dos direitos humanos. Por sua vez, ainda que haja algumas deficiências por parte de seu Sistema, esta tornou-se um fator essencial para prosperar princípios éticos, bem como direitos humanos fundamentais (LAFER, 1995).

Sendo assim, partindo de uma visão contemporânea dos direitos humanos, considerando-os como um conjunto de direitos essenciais para uma vida humana, a qual é pautada na liberdade, igualdade e dignidade (RAMOS, 2014) e, seguindo os preceitos positivados na Constituição Federal de 1988 e tratados internacionais, o Brasil reconhece que os direitos humanos existem para legitimar garantias mínimas para a vida, num contexto de harmonia social e justiça, considerando os princípios de liberdade, igualdade e desenvolvimento do ser humano.

Ainda, todavia, que sejam positivados interna e externamente, estes direitos não ganharam existência real para grande número de brasileiros. Desníveis regionais, marginalização social e discriminação social e econômica surgem com a distorção de preceitos legais e a não aplicação de princípios da C.F./88. Destaca-se que esta situação foi agravada na década de 90 do século 20, quando o governo brasileiro adotou a linha neoliberal, priorizando objetivos econômicos e financeiros em detrimento aos objetivos de cunho social (DALLARI, 2010).

Nesse sentido, considerando-se que ainda existe uma grande defasagem em relação às ações governamentais que visam à promoção e proteção desses direitos e, reconhecendo a importância atribuída a eles, a ONU surge com recomendações no campo dos direitos humanos que podem derivar de suas 30 agências especializadas, dezenas de tratados internacionais, cinco órgãos principais, o Sistema de Direitos Humanos, além do mecanismo de Revisão Periódica Universal (RPU), o qual será abordado neste artigo. Tal mecanismo aparece como um instrumento cooperativo, tendo como objetivo a identificação de "boas práticas", bem como "desafios" que visam a direcionar as necessidades dos Estados em consonância com a sustentação de suas competências nacionais no campo dos direitos humanos (BELLI, 2009).

À vista disso, o objetivo deste artigo consiste em analisar de que forma os instrumentos de planejamento - Planos Plurianuais - do governo federal incorporam as diretrizes e recomendações oriundas do mecanismo RPU sobre direitos humanos fundamentais. Para tanto, considera-se duas possibilidades: ao receber as recomendações o Estado pode ou não as aceitar; e, em caso positivo, as recomendações podem ou não ser incorporadas em seus instrumentos de planejamento. 


\section{Humanos e \\ Democracia}

Para cumprir com tal objetivo, dividimos este artigo em três partes, além desta introdução e considerações finais. Na primeira parte realizaremos um breve levantamento bibliográfico a respeito dos direitos humanos fundamentais, apresentando suas funções e características. Em seguida, abordaremos o histórico da ONU e suas influências perante os Estados-membros, além da apresentação do mecanismo RPU, o qual foi utilizado na etapa final desta pesquisa. Por fim, apresentaremos o levantamento e análise dos PPAs de 2008, 2012 e 2016 em consonância às recomendações de ambos os ciclos do mecanismo RPU, os quais foram realizados durante os anos de 2008 e 2012. Convém destacar que esta pesquisa utiliza uma metodologia aplicada mediante um estudo exploratório e descritivo analítico, o qual fora realizado por meio de revisões bibliográficas e dados secundários acerca do tema proposto.

\section{OS DIREITOS HUMANOS FUNDAMENTAIS: FUNÇÕES E CARACTERÍSTICAS}

Os direitos humanos constituem-se em uma construção histórica, da qual nascem de forma gradual, em determinadas circunstâncias, com a defesa de novas liberdades em oposição a velhos poderes (BOBBIO, 2014). Para Rosas (1995, p. 243), a concepção acerca dos direitos humanos é sempre progressiva, de modo que "o debate a respeito do que são os direitos humanos e como devem ser definidos é parte integrante de nossa história, de nosso passado e de nosso presente". À vista disso, Ramos (2014) ressalta que os direitos humanos se integram em um conjunto de direitos essenciais para uma vida humana, a qual é pautada na liberdade, $\mathrm{n}$ na igualdade e na dignidade. Mediante esta definição, o autor certifica que as necessidades humanas variam conforme o contexto histórico, do qual nascem novas demandas e estas são incorporadas na lista dos direitos humanos.

A concepção contemporânea de direitos humanos, como realça Piovesan (2013), deriva da internacionalização dos direitos, a qual surge a partir do Pós-Guerra em um cenário devastado pelo nazismo e descarte de pessoas. Neste contexto, nasce o impulso de reconstrução dos direitos humanos, o qual possui um ideal ético a fim de guiar a ordem internacional contemporânea (PIOVESAN, 2013).

No âmbito de tal debate, são atribuídas duas funções para tais direitos: a primeira consiste na função social e a segunda na função liberal. A função social dos direitos humanos refere-se à promoção da dignidade da pessoa humana, a qual diz respeito a um valor da ordem constitucional que transmite influências a todo o sistema jurídico e limita não somente as ações do Estado, mas também as relações privadas que se estendem pelo mercado e pela sociedade civil (SARMENTO, 2000 apud RAMOS, 2014). Por outro lado, a função liberal consiste na limitação do poder estatal, de modo que exista uma superioridade normativa na qual se torna inaceitável o atendimento de uma razão do Estado em detrimento de um direito essencial.

Além das funções apresentadas supra, os direitos humanos constituem-se em um conjunto de direitos que possuem algumas características principais. De acordo com Ramos (2014), os direitos humanos possuem quatro características: (i) universalidade, a qual consiste no reconhecimento de que todos são sujeitos de direitos, reprovando a visão de que alguns devem possuir privilégios por pertencer a determinada classe social ou, por alguma outra razão, serem superiores que os demais; (ii) essencialidade, referindo-se à visão de que os direitos humanos externalizam valores indispensáveis, devendo ser protegidos por todos; 
(iii) superioridade normativa, ou preferenciabilidade, que considera que os direitos humanos são superiores às demais normas, sendo inadmissível a privação de um direito essencial em virtude do atendimento de determinada razão do Estado; e (iv) reciprocidade, a qual consiste no conjunto dos direitos humanos, tanto no argumento de que todos possuem os mesmos direitos quanto na sujeição passiva, a qual se refere à proteção de direitos como um todo, não considerando que somente o Estado e seus agentes públicos devem protegê-los, mas, sim, sendo um dever da coletividade (RAMOS, 2014).

Carpizo (2011) apresenta outras características intrínsecas ao conjunto dos direitos humanos, podendo serem mais bem compreendidas no Quadro 1.

\section{Quadro 1 - Características inerentes aos direitos humanos}

\begin{tabular}{|c|c|c|}
\hline Universalidade & $\begin{array}{c}\text { Assim como é apresentado por Ramos (2014), esta característica refere-se à tese de que } \\
\text { todo ser humano é digno de um conjunto de direitos que independem do país em que } \\
\text { tenha nascido ou que esteja morando. Dessa forma, os direitos humanos agregam-se à toda } \\
\text { comunidade internacional, de forma que o Estado possua autonomia ao positivar direitos } \\
\text { em sua Constituição, não podendo violar as declaraçães e instrumentos internacionais que } \\
\text { ratificam tais direitos. }\end{array}$ \\
\hline Historicidade & $\begin{array}{c}\text { Considera três aspectos: a evolução da civilização, os novos problemas, necessidade e } \\
\text { desafios e o contexto social e cultural de cada país. Tal característica complementa-se } \\
\text { à universalidade, posto que considera que o reconhecimento e conteúdo dos direitos } \\
\text { humanos resultam da história e evolução da civilização, assim como a obrigação por parte } \\
\text { do Estado em respeitar os tratados internacionais de direitos humanos. }\end{array}$ \\
\hline Progressividade & $\begin{array}{c}\text { Tal característica está relacionada ao reconhecimento, de forma progressiva, dos direitos } \\
\text { humanos. Dessa forma, permite que novos direitos sejam incorporados nas Constituições, } \\
\text { ampliando os direitos já reconhecidos. }\end{array}$ \\
\hline Aspecto \\
protetor & $\begin{array}{c}\text { Consiste na qualidade de se proteger os direitos humanos da comunidade nacional, ou } \\
\text { seja, possui um caráter protetor fundamental no que diz respeito ao reconhecimento dos } \\
\text { direitos humanos. }\end{array}$ \\
\hline Indivisibilidade & $\begin{array}{c}\text { Considera que os direitos formam uma única unidade, uma vez que os mesmos são } \\
\text { interdependentes entre si, de forma que uns se apoiam em outros, integrando uma } \\
\text { unidade indivisivel. }\end{array}$ \\
\hline Eficácia direta & $\begin{array}{c}\text { Reconhece que os direitos positivados na Constituição e nos instrumentos internacionais } \\
\text { devem ser vinculados a todos os poderes públicos - Executivo, Legislativo, Judiciário e } \\
\text { demais organizações autônomas - de forma que se alcance os direitos humanos mediante a } \\
\text { existência da Lei. }\end{array}$ \\
\hline
\end{tabular}

Fonte: Elaboração própria a partir de CARPIZO (2011).

De acordo com o autor,

Todos los derechos humanos son universales, indivisibles e interdependientes y están relacionados entre sí. La comunidad internacional debe tratar los derechos humanos en forma global y de manera justa y equitativa, en pie de igualdad y dándoles a todos el mismo peso. Debe tenerse en cuenta la importancia de las particularidades nacionales y regionales, así como los diversos patrimonios históricos, culturales y religiosos, pero los Estados tienen el deber, sean cuales fueren sus sistemas políticos, económicos y culturales, de promover y proteger todos los derechos humanos y las libertades fundamentales (CARPIZO, 2011, p. 24). 
Desse modo, pode-se afirmar que o respeito à dignidade da pessoa humana deve consistir em uma diretriz máxima para as ações governamentais dos Estados soberanos, uma vez reconhecidos tais direitos. À vista disso, dando continuidade aos objetivos propostos para este trabalho, a próxima sessão busca apresentar o processo histórico de formação da Organização das Nações Unidas, assim como a evolução de suas preocupações em relação aos direitos humanos e o mecanismo de Revisão Periódica Universal.

\section{A ORGANIZAÇÃO DAS NAÇÕES UNIDAS E O MECANISMO DE REVISÃO PERIÓDICA UNIVERSAL}

Anteriormente ao advento da Primeira Guerra Mundial, a instituição de uma Organização Internacional com fins políticos e fundamentada mediante a continuidade e permanência por meio do gerenciamento conjunto de interesses comuns, já constituía uma ideia que perpassava o sistema internacional. No decorrer do pós-guerra, com a evidência de mais de nove milhões de mortos, houve a condução do posicionamento dos Estados Unidos no centro do mundo político internacional, em um contexto no qual a Europa encontrava-se dividida entre Estados fascistas, Estados capitalistas liberais e a Rússia comunista. A entrada dos Estados Unidos reverberou na última fase da Guerra e no pós-guerra em um papel decisório diante da construção de um projeto antecedente à ONU (XAVIER, 2007).

Em 8 de janeiro de 1918, o então presidente dos Estados Unidos, Woodrow Wilson, direcionou-se ao Congresso Nacional para proferir seus "14 pontos" para a restauração da paz. A partir dos pontos apresentados, foi fundado um Pacto que, durante a Conferência de Paz de 1919, foi integrado pelo Tratado de Paz de Versalhes e, apesar de se tratar de uma tentativa de restauração da paz, o Pacto foi às ruínas e, diante disso, os Países Aliados, ${ }^{1}$ durante a Segunda Guerra Mundial, trabalharam para uma nova institucionalização de uma Organização Internacional com um viés particularmente universal. Nesse contexto surge a Carta do Atlântico em 1941, sendo constituída em uma declaração conjunta entre o primeiro-ministro Britânico, Wilson Churchill e o presidente dos Estados Unidos, Roosevelt, abrangendo seis princípios fundamentais (XAVIER, 2007). De acordo com Ribeiro (1998, p. 33), os seis princípios declarados foram:

(i) o direito de todos os povos à segurança das suas fronteiras; (ii) o direito dos povos de escolherem a forma de governo sob a qual desejam viver; (iii) a igualdade de todos os Estados, vitoriosos e vencidos, de acesso às matérias-primas e de condições de comércio; (iv) a promoção da colaboração entre as nações com o fim de obter para todos melhores condições de trabalho, prosperidade e segurança social; (v) a liberdade de navegação; (vi) o desarmamento.

Em 1으 de janeiro de 1942 houve a adesão de 26 Estados à Carta do Atlântico, sendo motivados pelo combate ao Eixo Hitleriano. A partir desse momento, foi assinada a Declaração das Nações Unidas, em Washington, cujo nome serviu de inspiração para a nova Organização

\footnotetext{
No comando estavam os Estados Unidos, o Reino Unido e a antiga União Soviética. Outros países, entretanto, também integravam este grupo como forma de combate aos Países do Eixo, composto pela Alemanha nazista, Itália fascista e império do Japão.
} 
Internacional que seria institucionalizada a posteriori. Até março de 1945, outros 21 Estados uniram-se à Carta e se comprometeram a empenhar-se a favor destes princípios (XAVIER, 2007).

A Declaração de Moscovo, assinada em novembro de 1943, afirmava a necessidade de uma Organização Internacional fundamentada pelos princípios de igualdade entre os Estados, assegurando a manutenção da paz e a segurança internacional e, por intermédio desta, entre agosto e outubro de 1944, foi possível a apresentação de um projeto de Organização na Conferência de Dumbarton Oaks, resultando em um projeto denominado "Plano de Dumbarton Oaks" (XAVIER, 2007). Dando continuidade, ficou acordada a convocação de uma Conferência Internacional a ser realizada em São Francisco, estando presente as três potências vencedoras da Segunda Guerra Mundial e a China, assim como outras nações que decretaram guerra ao Eixo Hitleriano antes de março de 1945. Tal conferência teve início em 25 de abril e término em 26 de junho do mesmo ano (XAVIER, 2007).

É por meio desta Conferência Internacional que surge a Carta das Nações Unidas, a qual foi assinada em 26 de junho e passou a vigorar em 24 de outubro de 1945 . $^{2}$ Neste cenário, a Carta da Nações Unidas, assinada por 50 países, é o documento que marca a fundação da Organização das Nações Unidas (ONU), indicando uma delimitação do poder dos Estados-soberanos e, ao mesmo tempo, constitui-se em uma manifestação de anseio pela paz. A Carta transmite um teor ético à Organização Internacional, referindo-se a valores que vão além da concepção de que a paz é uma mera ausência de guerra, abrangendo os direitos humanos, a tolerância, a democracia, a cooperação e o anseio pelo desenvolvimento econômico (LAFER, 1995). Por se tratar de um tratado ambicioso e amplo, a ONU visava a cumprir com seus quatro propósitos fundamentais descritos na Carta (ONU, 1945a): (i) manter a paz e a segurança internacionais; (ii) desenvolver relações amigáveis entre as nações, sendo baseadas no respeito aos princípios de igualdade e autodeterminação dos povos; (iii) desenvolver uma cooperação internacional a fim de solucionar problemas de cunho econômico, social, cultural ou humanitário e o desenvolvimento e o incentivo ante o respeito aos direitos humanos; (iv) tornar-se um centro dedicado à harmonização de ações das nações para alcançar objetivos em comum.

Com efeito, a ONU foi fundada oficialmente em 24 de outubro de 1945, composta por países que se reuniram voluntariamente, surgindo neste cenário com o objetivo declarado de trabalhar pela paz e pelo desenvolvimento mundial. ${ }^{3}$ Seus princípios e valores foram acordados pelos Estados-membros, os quais comprometeram-se a maiores responsabilidades referente à proteção e promoção dos direitos humanos fundamentais, a fim de reconhecer e respeitar a dignidade da pessoa humana. ${ }^{4}$

Criada também em 1946, a Comissão de Direitos Humanos (CDH) projetou uma estratégia para o trabalho da ONU a partir do conceito de Carta Internacional dos Direitos Humanos, a qual englobava a produção de uma Declaração Universal, uma Convenção de Direitos Humanos e, também, a designação de medidas de execução.

\footnotetext{
Disponível em: https://nacoesunidas.org/carta/. Acesso em: 2 jan. 2016.

Atualmente a ONU conta com 193 membros, ganhando maior representatividade pela diversidade política e cultural.

4 Disponível em: http://nacoesunidas.org/conheca/historia/. Acesso em: 2 jan. 2016.
} 


\section{Humanos e \\ Democracia}

De acordo com Guerra e Oliveira (2009, p. 5),

A Comissão de Direitos Humanos contava com alguns grupos de trabalhos que tinham por finalidade a apresentação de estudos e atuação efetiva em vários assuntos relativos aos direitos humanos, tais como: i) Grupo de trabalho sobre detenção arbitrária; ii) Grupo de trabalho encarregado para a elaboração de um protocolo adicional para o Pacto Internacional sobre Direitos Econômicos, Culturais e Sociais; iii) Grupo de trabalho para elaboração de projeto relativo ao direito dos povos indígenas; iv) Grupo de trabalho sobre detenção arbitrária; v) Grupo de trabalho sobre o direito ao desenvolvimento.

A Declaração Universal dos Direitos Humanos - DUDH -, adotada em 10 de dezembro de 1948, é considerada um marco histórico e apresenta o repúdio aos regimes totalitários, além de representar um reconhecimento de que todos os indivíduos possuem dignidade e são sujeitos de direitos, os quais devem ser assegurados. A Declaração foi elaborada por representantes de diversos países e incorpora os direitos civis e políticos, econômicos, sociais e culturais; obteve 48 votos a favor e 8 abstenções e é considerada uma inspiração para inúmeras constituições de alguns Estados (LAFER, 1995). Um exemplo próximo é a Constituição Federal (C.F.) de 1988, na qual o Brasil manifesta uma preocupação evidente ao instituir direitos e garantias fundamentais à população.

A elaboração da Convenção de Direitos Humanos, no entanto, tornou-se problemática por conflitos ideológicos e dificuldades nas negociações, convertendo-se na elaboração de dois instrumentos que passaram a compor a Carta Internacional dos Direitos Humanos. Dessa forma, dois Pactos foram desenvolvidos: o primeiro refere-se aos Direitos Civis e Políticos, em conjunto com o Protocolo Opcional, e o segundo diz respeito aos Direitos Econômicos, Sociais e Culturais. Ambos foram adotados pela Assembleia Geral em 1966 e somente em 3 de janeiro de 1976 reuniram número satisfatório de ratificações para, então, poder entrar em vigência. Dessa forma, a Carta Internacional dos Direitos Humanos passou a ser composta pela DUDH e pelos Pactos supracitados. Ao aderir os Pactos, os Estados assumem duas obrigações: abstencionista (Pacto sobre Direitos Civis e Políticos) e adotar medidas para o cumprimento desses direitos (Pacto sobre Direitos Econômicos, Sociais e Culturais) (LAFER, 1995). Além da Carta Internacional, a ONU incorpora diversos instrumentos e tratados sobre direitos humanos, como a Convenção sobre a Eliminação de Todas as Formas de Discriminação Contra as Mulheres de 1979 e a Convenção sobre os Direitos da Criança de 1989, dentre outros.

Em 2006 a ONU criou um Conselho para suceder a Comissão de Direitos Humanos $(\mathrm{CDH})$, cuja razão fora a adulteração que o mesmo sofreu no decorrer de seus trabalhos, assim como pelas influências políticas de seus membros e equipes que comprometeram os princípios fundamentadores da DUDH (BELLI, 2009). Vale ressaltar que, durante muitos anos, o debate acerca dos direitos humanos ficou sob o controle de países mais poderosos, direcionando as atividades da Comissão para assuntos que estivessem diretamente ligados a suas intenções políticas, omitindo-se em relação a diversas violações ocorridas em todos os países (GUERRA; OLIVEIRA, 2009). Para fins ilustrativos, "nunca foi adotada nenhuma resolução condenando os abusos no Tibet e nada foi feito com relação à situação dos detentos na Baía de Guantánamo" (GUERRA; OLIVEIRA, 2009, p. 6). 
Em vista disso, a partir da descrença em relação ao comprometimento dos membros da Comissão e a consequente perda de credibilidade, houve a necessidade de renovar os trabaIhos deste Órgão. Para tanto, fora aderida a Resolução 60/251 em maio de 2006, instituindo o Conselho de Direitos Humanos, contando com a aprovação de 170 países $^{5}$ (GUERRA; OLIVEIRA, 2009). Ao mesmo tempo, tal resolução determinou a instauração do mecanismo de Revisão Periódica Universal (RPU) ou Universal Periodic Review (UPR), caracterizando-se como um instrumento cooperativo e que denota um processo construtivo, possibilitando projetar e emitir recomendações pontuais acerca do "compromisso com o sistema internacional de proteção de direitos humanos e sobre a situação interna de violações e práticas de proteção" (ANNONI; DOS SANTOS, 2015, p. 23).

Dessa forma, diante deste mecanismo, os Estados-membros passam a ser obrigados a responder às recomendações emitidas a cada novo ciclo, podendo ser derivadas tanto dos dados apresentados pelo próprio Estado sujeito à RPU quanto por informações levantadas pela ONU e, também, pela sociedade civil (ANNONNI; DOS SANTOS, 2015). Este mecanismo impõe que todos os Estados-membros da ONU sejam submetidos a esta revisão a cada quatro anos e meio, mensurando o compromisso assumido por Estado em fazer cumprir os direitos humanos.

A RPU é um exercício entre pares, ou seja, são os Estados que fazem perguntas e recomendações ao país que está sendo revisado durante sessão denominada "Diálogo Interativo" em Genebra (...). São 3 os documentos base da RPU: relatório oficial enviado pelo Estado sob revisão (EsR), relatório com informações dos órgãos e mecanismos da ONU sobre o EsR e uma compilação preparada pela ONU a partir das contribuições enviadas pela sociedade civil. ${ }^{6}$

Nessa perspectiva, tal mecanismo é caracterizado como um processo cíclico, sendo composto por três etapas fundamentais: (i) revisão da situação dos direitos humanos acerca do Estado-membro analisado; (ii) implementação das recomendações recebidas e compromissos assumidos pelo Estado-membro no período de quatro anos e meio; (iii) elaboração de um relatório acerca da implementação das recomendações e compromissos assumidos pelo Estado-membro para basear a próxima revisão. Vale ressaltar que uma recomendação consiste em uma sugestão realizada para o Estado-membro que está sendo analisado, a fim de contribuir com a real situação dos direitos humanos. Dessa forma, tal revisão ocorre por meio de um grupo de trabalho em Genebra/Suíça, sendo composto por todos os Estados-membros da ONU e dirigido pelo presidente do Conselho de Direitos Humanos. A partir desse momento, a revisão inicia-se com a apresentação do Estado que está sendo revisto, seguido pela discussão acerca da situação dos direitos humanos, o qual possui o direito de resposta em caso de questionamentos. Este processo tem duração de 3,5 horas, constituindo-se em uma ferramenta de avaliação das obrigações assumidas pelo Estado, tanto no que diz respeito à Carta Internacional dos Direitos Humanos quanto nos tratados ratificados pelo mesmo. ${ }^{7}$

\footnotetext{
Demais países, entretanto, votaram contra a criação do Conselho, como EUA, Israel, Ilhas Marshall e Palau. Houve também três abstenções oriundas da Venezuela, Iran e Belarus (GUERRA; OLIVEIRA, 2009).

6 Disponível em: http://www.conectas.org/pt/acoes/politica-externa/noticia/1-o-que-e-a-revisao-periodica-universal. Acesso em: 4 jun. 2016.

7 Disponível em: http://www.upr-info.org/en/upr-process/what-is-it. Acesso em: 4 jun. 2016.
} 


\section{Humanos e \\ Democracia}

De acordo com a Secretaria Especial de Direitos Humanos, ${ }^{8}$

o Governo brasileiro considera a adoção do mecanismo uma conquista histórica para a proteção dos direitos fundamentais por possibilitar, pela primeira vez na esfera internacional, que todos os Estados Membros da ONU sejam examinados (...) quanto à situação dos direitos humanos no plano interno.

Nesse sentido, em 2008 o Brasil passou pelo primeiro ciclo da RPU em Genebra, recebendo 15 recomendações de diversos países, comprometendo-se em cumprir com todas as sugestões recebidas, além de voluntariar-se em criar um sistema nacional de indicadores de direitos humanos, assim como elaborar um diagnóstico anual acerca da situação dos direitos humanos no país (CONECTAS, 2010). Em 2012 o país passou pelo segundo ciclo da RPU, recebendo 170 recomendações sobre direitos humanos. O detalhamento e análise acerca de ambos os ciclos, todavia, podem ser visualizados na sessão seguinte, a qual pretende apresentar de que forma as recomendações oriundas deste mecanismo são incorporadas nos instrumentos de planejamento do governo federal (PPAs).

\section{ANÁLISE DA INCORPORAÇÃO DAS RECOMENDAÇÕES DA ONU NAS AÇÕES GOVERNAMENTAIS}

Anteriormente à apresentação dos resultados desta pesquisa, torna-se necessário comentar brevemente a metodologia utilizada. Partindo de uma análise manual, identificamos as recomendações dos ciclos do mecanismo RPU ao Brasil correspondentes aos anos de 2008 e 2012, e correlacionamos estas com os objetivos e diretrizes dos instrumentos de planejamento do governo federal. Nesse sentido, para a realização desta etapa foram adotadas "palavras-chave" que caracterizavam as recomendações recebidas e, quando contempladas por algum objetivo ou diretriz dos PPAs, estes eram alocados em planilhas de acordo com rubricas que contemplavam a identificação posterior dos mesmos.

Desse modo, considerou-se duas possibilidades: ao receber as recomendações, o Estado brasileiro pode ou não as aceitar; em caso positivo, estas recomendações podem ou não ser incorporadas diretamente nos instrumentos de planejamento do governo federal. Quando definimos que uma recomendação foi incorporada diretamente, assumimos que os problemas e desafios elencados nesta foram considerados com precisão nas políticas públicas contidas no PPA analisado.

A análise das recomendações do ciclo I do mecanismo RPU foi realizada mediante sua sistematização e comparação com os PPAs de 2008-2011 e 2012-2015, a fim de compreender se tais recomendações foram incorporadas de alguma forma nesses instrumentos de planejamento e gestão estratégica. Da mesma forma, foi realizada a análise das recomendações do ciclo II do mecanismo RPU em paralelo ao PPA de 2016-2019. Com efeito, vale considerar que cada recomendação, de ambos os ciclos, foi analisada individualmente, podendo esta contemplar mais de um tema relativo aos direitos humanos fundamentais.

\footnotetext{
8 Disponível em: http://www.sdh.gov.br/assuntos/atuacao-internacional/programas/mecanismo-de-revisao-universal-dasnacoes-unidas-rpu. Acesso em: 4 jun. 2016.
} 
Parece oportuno, portanto, apresentar brevemente o papel do Plano Plurianual - PPA - como um instrumento de planejamento e gestão estratégica, tendo em vista a utilização deste instrumento como parte integrante da análise desta pesquisa.

O Plano Plurianual, estabelecido pela Constituição Federal de 1988, consiste em uma ferramenta que visa a "integrar o planejamento à execução das políticas públicas" (PAULO, 2010, p. 172). Dessa forma, caracteriza-se como um processo alocativo de recursos, quando o governo expressa direta ou indiretamente suas prioridades (CAVALCANTE, 2007).

De acordo com Paulo (2010, p. 184),

Para tornar efetivo o seu papel de planejamento e gestão estratégica, o PPA deve ser capaz de abrigar o debate político acerca da definição das metas. Para tanto, deve comportar maior flexibilidade metodológica e desvincular-se parcialmente da estrutura orçamentária, sendo capaz de mobilizar os tomadores de decisão e representar com clareza o compromisso político assumido.

É necessário lembrar que o PPA é apenas um instrumento de planejamento, o que não implica necessariamente a efetivação das políticas públicas contidas no mesmo. Em vista disso, podemos observar, a seguir, a quantidade de recomendações do ciclo I incorporada nos instrumentos de planejamento analisados.

Tabela 1 - Análise da incorporação das recomendações do Ciclo I do mecanismo RPU nos instrumentos de planejamento do governo federal

\begin{tabular}{ccc}
\hline & Quantidade & $\%$ \\
\hline Recomendações Aceitas & 15 & $100,00 \%$ \\
Recomendações Incorporadas no PPA 2008 & 10 & $66,67 \%$ \\
Recomendações Incorporadas no PPA 2012 & 14 & $93,33 \%$ \\
Recomendações Diretamente Incorporadas no PPA 2008 & 8 & $80,00 \%$ \\
Recomendações Diretamente Incorporadas no PPA 2012 & 11 & $78,57 \%$ \\
\hline
\end{tabular}

Fonte: Elaboração própria a partir da análise das recomendações do ciclo I em paralelo aos objetivos e diretrizes dos PPAs 2008-2011 e 2012-2015.

O ciclo I do mecanismo RPU, realizado em 2008, gerou um montante de 15 recomendações. O Estado brasileiro, por sua vez, aceitou todas (100\%). Apenas 10 recomendações $(66,67 \%)$, entretanto, puderam ser identificadas no PPA do ano de 2008. Dessas, somente 8 recomendações foram incorporadas diretamente ( $80 \%)$, ou seja, combatem propriamente os problemas e desafios elencados nas recomendações recebidas. No que diz respeito à análise das recomendações do ciclo I em relação ao PPA do ano de 2012, 14 recomendações (93,33\%) puderam ser identificadas neste instrumento. Dessas, apenas 11 foram diretamente incorporadas (78,57\%).

A fim de complementar a análise, foi possível identificar a quantidade de recomendações recebidas de acordo com a regionalização atribuída pela própria Nações Unidas, ${ }^{9}$ que se refere à alocação dos Estados-membros em Grupos Regionais. Dessa forma, cada Grupo diz respeito a um conjunto de Estados-membros. A Tabela 2 apresenta a porcentagem de recomendações proveniente desses Grupos.

\footnotetext{
Disponível em: http://www.un.org/depts/DGACM/RegionalGroups.shtml. Acesso em: 12 jul. 2016.
} 


\section{Democracia}

Tabela 2 - Grupo Regional das recomendações do Ciclo I do mecanismo RPU

\begin{tabular}{ccc}
\hline Grupo Regional & Quantidade de Recomendações & \% de recomendações \\
\hline Weog & 5 & $33,33 \%$ \\
África & 4 & $26,67 \%$ \\
Grulac & 4 & $26,67 \%$ \\
Ásia & 1 & $6,67 \%$ \\
EEG & 1 & $6,67 \%$ \\
\hline
\end{tabular}

Fonte: Elaboração própria a partir dos dados da Database RPU Info. ${ }^{10}$

Como podemos visualizar, a maior parte das recomendações centra-se nos Grupos Weog (33,33\%), África (26,67\%) e Grulac (26,67\%). O Grupo Weog corresponde às recomendações recebidas pelos seguintes países: Reino Unido (2 rec.), Bélgica (1 rec.), Alemanha (1 rec.) e Holanda (1 rec.). O Grupo África corresponde às recomendações dos países: Gana (2 rec.), Argélia (1 rec.) e Nigéria (1 rec.). O Grupo Grulac diz respeito às recomendações provenientes dos países: México (2 rec.), Uruguai (1 rec.) e Peru (1 rec.).

A Tabela 3 apresenta a análise referente ao ciclo II do mecanismo RPU com base no PPA de 2016-2019.

Tabela 3 - Análise da incorporação das recomendações do Ciclo Il do mecanismo RPU nos instrumentos de planejamento do governo federal

\begin{tabular}{ccc}
\hline & Quantidade & $\%$ \\
\hline Recomendações Aceitas & 169 & $99,41 \%$ \\
Recomendações Incorporadas no PPA 2016 & 134 & $78,82 \%$ \\
Recomendações Diretamente Incorporadas no PPA 2016 & 88 & $51,76 \%$ \\
\hline
\end{tabular}

Fonte: Elaboração própria a partir da análise das recomendações do ciclo II em paralelo aos objetivos e diretrizes do PPA 2016-2019.

O ciclo II do mecanismo RPU, realizado em 2012, gerou um montante de 170 recomendações. Diferentemente do ciclo I, o Estado brasileiro rejeitou apenas uma recomendação $(99,41 \%)$, a qual diz respeito à separação de polícias militares com o intuito de reduzir as execuções extrajudiciais. Dessa forma, foi possível identificar o atendimento de 134 recomendações $(78,82 \%)$. Dessas, apenas 88 recomendações $(51,76 \%)$ atenderam diretamente os desafios e problemas elencados. Na Tabela a seguir identificamos a porcentagem de recomendações recebidas de acordo com os Grupos Regionais.

Tabela 4 - Grupo Regional das recomendações do Ciclo II do mecanismo RPU

\begin{tabular}{ccc}
\hline Grupo Regional & Quantidade de Recomendações & \% das 170 recomendações \\
\hline WEOG & 52 & 30,59 \\
Ásia & 38 & 22,35 \\
Grulac & 26 & 15,29 \\
África & 22 & 12,94 \\
EEG & 21 & 12,35 \\
Observer & 11 & 6,47 \\
\hline
\end{tabular}

Fonte: Elaboração própria a partir dos dados da Database RPU Info.

\footnotetext{
${ }^{10}$ Disponível em: http://www.upr-info.org/database/. Acesso em: 12 mar. 2016.
} 
Como observado na Tabela 4, a grande parte das recomendações deste II ciclo são provenientes dos Grupos Weog (30,59\%) e Ásia (22,35\%). Os países recomendadores do Grupo Weog são: Turquia (5 rec.), Espanha (5 rec.), França (4 rec.), Holanda (4 rec.), Portugal (3 rec.), Austrália (3 rec.), Suíça (3 rec.), Estados Unidos (3 rec.), Canadá (3 rec.), Noruega (3 rec.), Bélgica (3 rec.), Suécia (2 rec.), Reino Unido (2 rec.), Dinamarca (2 rec.), Finlândia (2 rec.), Grécia (2 rec.), Alemanha (2 rec.) e Itália (1 rec.).

Em contrapartida, os países recomendadores do Grupo Ásia são: Irã (5 rec.), Iraque (4 rec.), Nepal (3 rec.), Indonésia (2 rec.), Malásia (2 rec.), Catar (2 rec.), Japão (2 rec.), República da Coreia (2 rec.), Tailândia (2 rec.), Uzbequistão (2 rec.), Singapura (2 rec.), Vietnã (2 rec.), Paquistão (2 rec.), Filipinas (1 rec.), Arábia Saudita (1 rec.), Líbano (1 rec.), Sri Lanka (1 rec.), Timor-Leste (1 rec.) e China (1 rec.).

É importante ressaltar que o aumento considerável do número de recomendações entre ambos os ciclos, passando de 15 para 170, foi derivado, principalmente, pelo aumento do número de Estados-membros que participaram do II ciclo do mecanismo RPU. No primeiro ciclo as recomendações foram derivadas de 44 países, enquanto no segundo foram oriundas de 78 países. Da mesma forma, este aumento de recomendações foi possível por meio da incorporação de outros temas no processo de acompanhamento do RPU, assim como derivado da centralização do debate sobre a aplicação das recomendações direcionadas ao país durante o I ciclo. Dessa forma, ressalta-se que todos os temas das recomendações do I ciclo apareceram no II ciclo desta Revisão, de modo com que estes fossem acompanhados e revisados.

No que diz respeito à análise das recomendações individuais de ambos os ciclos, percebeu-se que algumas apresentam-se de forma complexa, elencando diversos tipos de direitos. Em outras, foi necessário recorrer a documentos secundários para balizar a análise. Como exemplo podemos citar as recomendações que se referem ao estabelecimento de uma Instituição Nacional de proteção aos direitos humanos que siga os Princípios de Paris. ${ }^{11}$ Tal recomendação esteve presente em ambos os ciclos.

Ademais, grande parte das recomendações assemelham-se e, muitas vezes, várias recomendações acabaram sugerindo um mesmo encaminhamento para a solução de um único desafio ou problema identificado. Estas, por sua vez, poderiam passar por um processo de sistematização, no qual fosse possível utilizar apenas uma recomendação que contemplasse os problemas identificados. Em contrapartida, a quantidade de recomendações, direcionadas a um determinado tema, caracteriza o grau de importância e complexidade do desafio reconhecido. Destaca-se que a maioria das recomendações do ciclo I referenciavam-se à "situação de pessoas privadas de liberdade" e à "atuação policial e segurança pública". No que diz respeito ao ciclo II, a maioria das recomendações diziam respeito à "legislação, políticas públicas, instituições e boa governança" e aos "direitos humanos de mulheres"; este último tema possui relação com uma das recomendações do ciclo I do mecanismo, a qual recomendava que fosse incorporada a perspectiva de gênero no processo de acompanhamento da Revisão Periódica.

\footnotetext{
${ }^{11}$ Os Princípios de Paris, definidos pela ONU em março de 1992, atribuem cinco características fundamentais para as Instituições Nacionais de Direitos Humanos, são elas: (i) autonomia, com o propósito de monitorar quaisquer violações de direitos humanos; (ii) autoridade para auxiliar os Poderes Executivo e Legislativo e demais instâncias que trabalham com temas relacionados aos direitos humanos; (iii) capacidade de estabelecer relações com instituições regionais e internacionais; (iv) legitimidade para educar em direitos humanos; e (v) competência jurídica.
} 


\section{Humanos e \\ Democracia}

Dessa forma, podemos afirmar que, ainda que tenha ocorrido um aumento significativo do número de recomendações e temas entre ambos os ciclos, estas tornaram-se mais genéricas e repetitivas. Mesmo diante da imprecisão de diversas recomendações, no entanto, o Estado brasileiro incorporou grande parte delas em seus instrumentos de planejamento, como pode ser revisto nas Tabelas 1 e 3. De todo modo, é importante ressaltar que o PPA é apenas um instrumento de planejamento, não implicando, necessariamente, a efetivação das políticas públicas contidas no Plano.

Diante da análise proferida, e reconhecendo os princípios que regem a ONU sobre a temática dos direitos humanos, é possível questionar sobre como este mecanismo interfere nos Estados-membros. Esta indagação baseia-se no pressuposto de que, mesmo que os Estados-membros estejam se empenhando na aferição de recomendações, os Estados-membros revisados não possuem uma obrigação em segui-las e, muito menos, são pressionados pela própria Nações Unidas sobre a adoção das mesmas. Em vista disso, consequentemente, a mudança do cenário dos direitos humanos no âmbito dos Estados-membros, a qual é prevista desde a adoção deste mecanismo pelo Conselho de Direitos Humanos da ONU, não se concretiza efetivamente.

\section{CONSIDERAÇÕES FINAIS}

A ideia central que perpassa o debate acerca dos direitos humanos consiste na proteção da dignidade da pessoa humana, o que significa que há o reconhecimento de que todos somos sujeitos de direitos. Nesse sentido, ações governamentais tornam-se necessárias a fim de garantir tais direitos, os quais são positivados direta e indiretamente nos âmbitos interno e externo.

Dessa forma, partindo do pressuposto de que estes direitos não ganharam existência real para grande parte das pessoas, a ONU surge com recomendações de diversas fontes, buscando modificar o cenário dos direitos humanos na esfera dos Estados-membros, a fim de contribuir para a proteção da dignidade da pessoa humana.

O mecanismo de Revisão Periódica Universal (RPU/ONU) tornou-se um instrumento reconhecido como "inovador", sendo introduzido pelo Conselho de Direitos Humanos, o qual analisa e avalia a situação dos direitos humanos e o cumprimento das obrigações assumidas. Ainda que recomendações sejam direcionadas aos Estados-membros, entretanto, estes podem ou não as aceitar, não sendo obrigatórias. O Brasil, ao participar de dois ciclos desta Revisão, aceitou quase todas as recomendações, todavia nem todas foram incorporadas diretamente em seus instrumentos de planejamento e gestão estratégica, ou seja, não combatem propriamente os problemas e desafios elencados nas recomendações recebidas. Ademais, no que diz respeito às recomendações incorporadas diretamente, estas podem não ter relação direta com as recomendações recebidas, uma vez que podem ser fruto de debates internos, bem como prioridades atribuídas pelo próprio governo. Da mesma forma, estas podem não ter sido efetivadas em sua totalidade, uma vez que analisamos apenas um instrumento de planejamento do governo federal.

Em vista disso, retoma-se o questionamento sobre como o mecanismo a RPU interfere na atuação da ONU sobre os Estados-membros, revendo este caráter "inovador" que lhe foi atribuído. A ONU não exerce nenhum tipo de influência sobre os Estados-membros após o 
recebimento das recomendações. Dessa forma, deixa livre sua adoção e efetivação, tornando-se passível em relação às suas prioridades. Sendo assim, somente a partir do momento em que existir um maior pressionamento sobre sua adesão, mesmo que seja apenas sobre os temas mais abordados nas recomendações, tornar-se-á possível a modificação do cenário real dos direitos humanos no âmbito dos Estados-membros.

\section{REFERÊNCIAS}

ANNONI, D.; DOS SANTOS, J. P. O Conselho de Direitos Humanos das Nações Unidas e a Revisão Periódica Universal: o que mudou no Brasil em matéria de política pública de segurança para o sistema prisional após dois ciclos de monitoramento? Revista de Estudos Internacionais, v. 6, n. 1, p. 22-39, 2015.

BELLI, Benoni. A politização dos direitos humanos: o Conselho de Direitos Humanos das Nações Unidas e as resoluções sobre países. São Paulo: Perspectiva, 2009.

BOBBIO, Norberto. A era dos direitos. Tradução Carlos Nelson Coutinho. Rio de Janeiro: Elsevier; Campus, 2014. BRASIL. Secretaria Especial de Direitos Humanos. Ministério da Justiça e Cidadania. Participação na Revisão Periódica Universal (RPU): processo universal realiza revisão do cumprimento das obrigações e compromissos do Estado. Disponível em: http://www.sdh.gov.br/assuntos/atuacao-internacional/programas/mecanismo-de-revisao-universal-das-nacoes-unidas-rpu. Acesso em: 4 jun. 2016.

CARPIZO, Jorge. Los derechos humanos: naturaleza, denominación y características. Cuestiones Constitucionales, n. 25, p. 3-29, jul./dez. 2011.

CAVALCANTE, Pedro Luiz. O Plano Plurianual: resultados da mais recente reforma do Planejamento e Orçamento no Brasil. Revista do Serviço Público, v. 58, n. 2, p. 129-150, 2010.

CONECTAS. O que é a revisão periódica universal? 2010. Disponível em: http://www.conectas.org/pt/acoes/politica-externa/noticia/1-o-que-e-a-revisao-periodica-universal. Acesso em: 4 jun. 2016.

DALLARI, Dalmo de Abreu. O Brasil rumo à sociedade justa. In: SILVEIRA, Rosa Maria Godoy et al. Educação em Direitos Humanos: fundamentos teórico-metodológicos. Brasília: Secretaria Especial dos Direitos Humanos, 2010. p. 29-49.

GUERRA, S. C. S.; OLIVEIRA, C. L. Da Comissão ao Conselho de Direitos Humanos: uma mudança mais que institucional? Revista de Direito da Unigranrio, v. 2, n. 1, 2009.

LAFER, Celso. A ONU e os direitos humanos. Estudos Avançados, v. 9 n. 25, p. 169-185, 1995.

ONU. Organização das Nações Unidas. A Carta das Nações Unidas. 1945a. Disponível em: https://nacoesunidas. org/carta/. Acesso em: 2 jan. 2016.

ONU. Organização das Nações Unidas. A história da organização. 1945b. Disponível em: http://nacoesunidas. org/conheca/historia/. Acesso em: 2 jan. 2016.

PAULO, Luiz Fernando Arantes. O PPA como instrumento de planejamento e gestão estratégica. Revista do Serviço Público, v. 61, n. 2, p. 171-187, 2010.

PIOVESAN, Flávia. Direitos humanos e justiça internacional: um estudo comparativo dos sistemas regionais europeus, interamericano e africano. São Paulo: Saraiva, 2013.

PIOVESAN, Flávia. Direitos sociais, econômicos e culturais e direitos civis e políticos. SUR - Revista Internacional de Direitos Humanos, n. 1, p. 20-47, 2004.

RAMOS, André de Carvalho. Curso de direitos humanos. São Paulo: Saraiva, 2014.

RIBEIRO, Manuel de Almeida. A Organização das Nações Unidas. Coimbra: Livraria Almedina, 1998.

ROSAS, Allan. So-called rights of the third generation. In: EIDE, Asbojorn et al. Economic, Social and Cultural Rights. Dordrecht; Boston; Londres: Martins Nijhoff Publisher, 1995.

UNITED NATIONS. Database on the Universal Periodic Review recommendations and voluntary pledges. Disponível em: http://www.upr-info.org/database/. Acesso em: 12 mar. 2016 a.

UNITED NATIONS. Department for General Assembly and Conference Management. United Nations Regional Groups of Member States. Disponível em: http://www.un.org/depts/DGACM/RegionalGroups.shtml. Acesso em: 12 jul. 2016b.

UPR-INFO. What is the UPR? Disponível em: http://www.upr-info.org/en/upr-process/what-is-it. Acesso em: 4 jun. 2016.

XAVIER, Ana Isabel. ONU: A Organização das Nações Unidas. In: XAVIER, Ana Isabel et al. A Organização das Nações Unidas. Coimbra: Humana Global; Associação para a Promoção dos Direitos Humanos, da Cultura e do Desenvolvimento, 2007. p. 9-174. 